\title{
(C) OPEN ACCESS \\ 'Not another safety culture survey': using the Canadian patient safety climate survey (Can-PSCS) to measure provider perceptions of PSC across health settings
}

\author{
Liane R Ginsburg, ${ }^{1}$ Deborah Tregunno, ${ }^{2}$ Peter G Norton, ${ }^{3}$ \\ Jonathan I Mitchell, ${ }^{4}$ Heather Howley ${ }^{4}$
}

\section{- Additional material is published online only. To view please visit the journal online (http://dx.doi.org/10.1136/bmjgs- 2013-002220). \\ ${ }^{1}$ School of Health Policy and Management, York University, Toronto, Ontario, Canada \\ ${ }^{2}$ School of Nursing, Queen's University, Kingston, Ontario, Canada \\ ${ }^{3}$ Department of Family Medicine (Emeritus), University of Calgary, Calgary, Canada \\ ${ }^{4}$ Accreditation Canada, Ottawa, Ontario, Canada}

\section{Correspondence to}

Dr Liane R Ginsburg, School of Health Policy and Management, York University, HNES Bldg. Rm 413, 4700 Keele Street, Toronto, ON, Canada M3J 1P3; lgins@yorku.ca

Received 10 June 2013 Revised 22 August 2013 Accepted 21 September 2013 Published Online First

11 October 2013

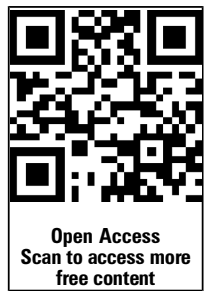

To cite: Ginsburg $L R$, Tregunno D, Norton PG, et al. BMJ Qual Saf 2014;23: 162-170.

\begin{abstract}
Background The importance of a strong safety culture for enhancing patient safety has been stated for over a decade in healthcare. However, this complex construct continues to face definitional and measurement challenges. Continuing improvements in the measurement of this construct are necessary for enhancing the utility of patient safety climate surveys (PSCS) in research and in practice. This study examines the revised Canadian PSCS (Can-PSCS) for use across a range of care settings.
\end{abstract}

Methods Confirmatory factor analytical approaches are used to extensively test the CanPSCS. Initial and cross-validation samples include 13126 and 6324 direct care providers from 119 and 35 health settings across Canada, respectively.

Results Results support a parsimonious model of direct care provider perceptions of patient safety climate (PSC) with 19 items in six dimensions: (1) organisational leadership support for safety; (2) incident follow-up; (3) supervisory leadership for safety; (4) unit learning culture; (5) enabling open communication I: judgement-free environment; (6) enabling open communication II: job repercussions of error. Results also support the validity of the Can-PSCS across a range of care settings.

Conclusions The Can-PSCS has several advantages: (1) it is a theory-based instrument with a small number of actionable dimensions central to the construct of PSC; (2) it has robust psychometric properties; (3) it is validated for use across a range of care settings, therefore suitable for use in regionalised health delivery systems and can help to raise expectations about acceptable levels of PSC across the system; (4) it has been tested in a publicly funded universal health insurance system and may be suitable for similar international systems.

\section{BACKGROUND}

The importance of a strong safety culture for enhancing patient safety has been stated for over a decade in healthcare. ${ }^{12}$ Increasing empirical evidence supports the relationship between staff perceptions of safety culture and safety behaviours ${ }^{3} 4$ and outcomes in healthcare ${ }^{5-8}$ and in other industries. ${ }^{9-11}$ In addition, recent work has found strong positive relationships between staff perceptions of safety culture and family member satisfaction ${ }^{12}$ and patient satisfaction. ${ }^{13}$ In organisations with health professional trainees, safety culture has a vital role, albeit not always positive, ${ }^{14}$ in imparting the importance of patient safety (PS) for effective practice. ${ }^{15}$ The importance of culture is further reflected in the crucial role it has played (1) in the Keystone work to reduce central line-associated bloodstream infections in the intensive care unit (ICU) ${ }^{16}$ and (2) in the successful use of surgical safety checklists ${ }^{17}{ }^{18}$ - two of the most effective, evidence-based patient safety improvement interventions to date. ${ }^{1920}$

Given the importance of patient safety culture and ongoing challenges in our ability to measure safety improvements, ${ }^{16}$ the need for robust measures is clear. Safety climate is a perceptual measure that can serve as a window through which culture can be viewed ${ }^{21}$ (see the 'Construct' section below for a more detailed discussion of culture and 
climate). Several patient safety climate (PSC) instruments have been developed and are widely used. Researchers have advanced construct measurement of PSC through the use of relational approaches that focus on convergent and discriminant validity ${ }^{22}$ and through the use of exploratory and confirmatory factor analytical approaches designed to identify unique PSC dimensions. ${ }^{23-25}$ However, despite these advances in PSC measurement, challenges persist. It was recently pointed out ${ }^{26}$ that PSC measures have become increasingly broad, and strong evidence of psychometric rigour remains limited for perceptual measures of PSC $^{27}$ (see box 1).

Persistent PSC measurement challenges mean that continued efforts are required to strengthen existing models and measures. The revised ${ }^{28}$ Canadian Patient Safety Climate Survey (Can-PSCS) provides a parsimonious measure of direct care providers' perceptions of PSC and has been adopted for use by Accreditation Canada. This paper reports on the psychometric properties of the Can-PSCS, including its suitability for use across different care settings.

\section{Do we really need another PSC survey?}

The Can-PSCS can help to deal with three challenges - survey length, national validation and psychometric rigour (see box 1) -and offers the following benefits: (1) most importantly, in contrast to recent work, to create or modify PSC surveys for use in specific sectors, ${ }^{23} 2930$ the Can-PSCS is designed and tested for use across a variety of care settings-an instrument that can be used across settings is particularly well suited to regionalised health delivery systems and can help to raise expectations about acceptable levels of

\section{Box 1 Persistent challenges of PSC measurement}

- PSC is increasingly defined using a broad set of dimensions, ${ }^{28}$ which Singer and Vogus suggest, 'dilute this domain'. ${ }^{26}$ More parsimonious models and shorter surveys are required to facilitate use of data on PSC perceptions. ${ }^{26}$

- PSC factor structures are not replicated in UK, ${ }_{1}^{31}$ Swiss $^{32}$ and French ${ }^{33}$ samples but supported in others $^{34}$ (perhaps owing to unique country characteristics, types of health systems, samples, cultural differences). ${ }^{32}$

- Many PSC dimensions often fail to achieve reliable internal consistency. ${ }^{31} 35$

- Strong evidence of psychometric rigour using independent samples for cross-validation (ie, EFA and CFA performed on separate samples $)^{36}$ remains limited.

CFA, confirmatory factor analysis; EFA, exploratory factor analysis; PSC, patient safety climate.
PSC across the system; (2) its psychometric properties are among the most robust of PSC surveys; (3) it is based on sound theoretical approaches and includes a small number of actionable dimensions central to the construct of PSC; and finally (4) the Can-PSCS has been tested in a publicly funded universal health insurance system - a system similar to that found in many European and other international contexts.

Ultimately, we require sound measures of PSC in order to be able answer other important (and, indeed, more interesting) questions about PSC, such as whether we can account for which PSC dimensions can differentiate units or organisations, which dimensions have shown the strongest relationship with outcomes and which dimensions are most amenable to intervention and change.

\section{The construct}

The concepts of organisational culture and climate have been around since the 1970s; however, three recent papers ${ }^{21} 3738$ from the fields of organisational behaviour and industrial/organisational psychology make important contributions about these constructs. Climate is an experientially based perception of what happens to people in an organisational situation. ${ }^{37}$ It involves employees' perceptions of the procedures, practices and kinds of behaviours that get rewarded and supported with regard to a specific strategic focus such as patient safety. ${ }^{21}$ Culture resides at a deeper level and can be defined as the shared basic assumptions, values and beliefs that characterise a setting ${ }^{38}$ and helps define why things happen in an organisation. ${ }^{37}$ Climate and culture are increasingly viewed as complementary constructs ${ }^{21}$ that reflect an important aspect of organisational context. ${ }^{37}$ Schein $^{39}$ recently characterised climate as providing the behavioural evidence for the culture of a setting-put differently 'Climate can serve as a window through which organisational culture can be viewed'. ${ }^{21}$ Culture and climate are multilevel constructs in that employees develop climate perceptions of the overall organisational climate as well as perceptions of the group/subunit level climate in which they work. ${ }^{21}$ These perceptions may be consistent or discrepant, but both are important predictors of safety behaviour. ${ }^{40}$

Climate should be conceptualised and measured in a focused, ${ }^{38}$ domain-specific ${ }^{40}$ way rather than as a global measure (eg, climate measures should focus on safety or some other strategic area). Moreover, members of the organization should be evaluating (1) the importance of the strategic area of focus (eg, safety) relative to other strategic priorities; (2) the alignment between espoused and enacted priorities (eg, what leadership says vs what they do); and (3) the consistency between organisational level policies and procedures and implementation practices in subunits that are subject to supervisory discretion. 
The theoretical model for the Can-PSCS is in keeping with the above principles and is rooted in Zohar's ${ }^{41} 42$ and Hofmann and Mark's ${ }^{5}$ work on safety climate. The Can-PSCS dimensions of Organisational leadership for safety and Supervisory leadership support for safety are supported by Zohar's definition of safety climate as management commitment to, ${ }^{41}$ and prioritisation ${ }^{43}$ of, safety by leadership at multiple levels. ${ }^{42}$ The Can-PSCS dimensions of Patient safety learning culture and Communicating/ talking about errors are consistent with Hofmann and Mark's ${ }^{5}$ model of safety climate, which draws on the error literature and places emphasis on 'constructively responding to errors, openly communicating about these errors and the extent to which the social context encourages or discourages these behaviours' (2006: 849).

Finally, the terms culture and climate are often used interchangeably. ${ }^{44}$ Organisational leaders tend to be unconcerned with distinctions between the two constructs and culture seems to be their preferred term, ${ }^{38}$ but the Can-PSCS is technically a measure of climate and is described as such from here. ${ }^{\mathrm{i}}$

\section{METHODS}

In this study we used survey data collected from staff in a large, cross-sectional sample of Canadian healthcare organisations to examine the factor structure of the Can-PSCS and determine scale internal consistency. Survey data were collected in 2011 by Accreditation Canada as part of the Qmentum accreditation programme. ${ }^{45}$

\section{Sampling and procedures}

Accreditation Canada provided the lead author with all anonymised Can-PSCS data collected between April and October 2011 as part of the Qmentum accreditation process ('the initial sample'). From the initial sample we used data from 13 126/16 410 $(80 \%)$ responders in 119 organisations whose job category was self-reported as 'direct care to clients'. Accreditation Canada provided a second anonymised dataset for cross-validation ('the cross-validation sample') that included survey responses from 6324 direct care providers in 35 additional organisations that deployed the Can-PSCS in November and December 2011. Focusing on data from direct care providers remains true to the construct definition of 'employee perception of PSC'.

${ }^{\mathrm{i}}$ Previously the Can-PSCS was described as a culture survey since culture was the term more commonly used in practice settings. This approach was in keeping with views of safety climate as a surface manifestation of safety culture (Schein, 1990). For consistency purposes and to respond to the Canadian practice environment, Accreditation Canada refers to the Can-PSCS as the Canadian Patient Safety Culture Survey.
These organisations represent the continuum of care and the 13126 direct care providers came from hospitals (28\%), nursing homes (32\%), ambulatory and community-based health organisations (14\%), homecare agencies (5\%), mental health (7\%) and other settings. Most hospitals and a large proportion of other healthcare organisations in Canada participate in the Accreditation Canada process which operates on a 4-year cycle. During each cycle organisations distribute the PSC survey for completion. In an effort to ensure data are representative, a minimum number of responses are set by Accreditation Canada based on the number of staff in each organisation. However, because distribution of the questionnaire ultimately resides with each organisation, Accreditation Canada does not have access to the data necessary to accurately calculate survey response rates for each organisation. Details on the Accreditation Canada Qmentum accreditation programme and processes for survey data collection are provided in the online supplementary technical appendix.

Because the data we report in this paper were provided in anonymised form to the lead author for secondary analyses, the results were exempt from review by the Office of Research Ethics at York University where the lead author is employed.

\section{Survey development}

The Can-PSCS was designed to capture staff perceptions of patient safety culture. Earlier versions of the instrument (described previously ${ }^{28} 46$ ) were adapted from work by Singer and colleagues, ${ }^{47}$ Hofmann $^{5}$ and the Agency for Healthcare Research and Quality (AHRQ) ${ }^{48}$ and included selected items and dimensions suited to the Canadian context. In 2010 the instrument underwent a major revision to improve its factor structure and yield a more parsimonious, theory-based measurement model of PSC. This revision was undertaken with insights described above regarding the conceptualisation and measurement of PSC in mind. The 2010 revision focused on identifying a series of items to comprehensively measure the area of Communicating and talking about errors. As early as $1980,{ }^{41}$ Zohar identified 'communication' as vital to safety climate. More recently others drew attention to the importance of openly communicating about errors and the extent to which the social context encourages or discourages this. ${ }^{5}$ Details of the revision are provided in the online supplementary appendix under 'Survey revision process'.

The 2010 Can-PSCS contained 38 items designed to reflect (1) management commitment to safety at the organisational level (Organisational leadership for safety - seven items adapted from the Patient Safety Climate in Healthcare Organizations (PSCHO $)^{47}$ ); (2) immediate supervisory-level commitment to safety (Supervisory leadership support for safety-five items adapted from the AHRQ PSC survey ${ }^{35}$ ); 
constructive response to errors (Patient safety learning culture-six items adapted from Hofmann ${ }^{5}$ ) and (4) open communication/talking about errors (20 items that emerged from the survey revision process outlined in the online supplementary appendix). These four areas are consistent with robust models of safety climate that have been shown to predict safety outcomes. ${ }^{5}{ }^{43}$ All items are answered using a five-point disagree-agree Likert-type scale and include a 'not applicable' option.

\section{Analysis}

The validation work described here involved all 38 items on the 2010 survey. Although the domains of PSC in the 2010 survey were theoretically derived, the construct of patient safety culture has been described as having the 'definitional precision of a cloud'. ${ }^{49}$ Given this definitional imprecision and the large-scale nature of the changes to the 2010 survey, we carried out exploratory factor analysis (EFA) followed by confirmatory factor analysis (CFA) using two separate random samples of 3000 cases drawn from our large initial sample. CFA is a measurement model which depicts the links between latent variables (in this case the PSC dimensions) and their observed measures-the items used to measure each of these dimensions. $^{50}$

We used AMOS V.7 (SPSS, Inc, Chicago, Illinois, USA) and performed a series of six CFAs. The model that emerged from the EFA was tested in CFA-1 and did not demonstrate good fit. Modified models with fewer items were tested in CFA-2 and CFA-4. With such retrofitting of a model to the data (eg, removing items that are not well accounted for by the model), standard psychometric practices for establishing construct validity require use of a separate (crossvalidation) sample ${ }^{51}$ - this was done in CFA-6 using the validation sample provided by Accreditation Canada. CFA-3 and CFA-5 used multiple group CFA techniques $^{50}$ to test the validity of CFA-2 and CFA-4, respectively, for measurement invariance across five different care settings: acute care medicine, long-term care, homecare, community care and ambulatory care.

The comparative fit index (CFI) and the root mean square error of approximation (RMSEA) were used to evaluate model fit in all CFA models. Models with CFI values $>0.95$ and RMSEA values $<0.06$ are indicative of good model fit. ${ }^{36}$ These criteria have been used previously in medical education research. ${ }^{52}$ Given controversy surrounding their use, $\chi^{2}$ values are provided and discussed only in the paper's online supplementary appendix along with other fit indices (goodness-of-fit index, adjusted goodness of fit and $\chi^{2}$ to $\mathrm{df}$ ratio). Slightly different metrics are required to evaluate multiple group CFA. ${ }^{50}$ Accordingly, CFA-3 and CFA- 5 model fit would be supported by nonsignificant $\chi^{2}$ difference values and by changes in $\mathrm{CFI}<0.01$. Finally, internal consistency reliability of the final dimensions of PSC was examined using Cronbach's $\alpha$ coefficients for all care settings combined and for the five separate care settings noted above.

\section{RESULTS}

\section{Respondents}

Because complete data are required for CFA, listwise deletion of incomplete data was used. Seventy-six per cent of direct care providers in the initial sample (9978/13 126) provided complete data. From these 9978 cases we randomly selected two samples of 3000 cases for the EFA and CFA-1, respectively. Using the initial sample, the multiple group CFA (CFA-3 and CFA-5) included all 788, 544, 147 and 536 cases from acute care medicine, homecare, community care and ambulatory care, respectively. Additionally, a random sample of 568 cases from long-term care was used as a much larger proportion of respondents were from this sector than from the other sectors examined. In the cross-validation sample (CFA-6) listwise deletion of incomplete data yielded 5296 usable cases for analysis.

\section{Factor structure and reliability of the Can-PSCS}

A six-factor model with the following properties emerged as the strongest model in the EFA: (1) the Organisational leadership for safety, Supervisory leadership support for safety and Patient safety learning culture dimensions retained from previous versions of the survey were largely supported; (2) the 20 items added to the 2010 survey to reflect Communication and talking about errors factored into unique dimensions with one exception-four items that ask about managerial feedback and follow-up about errors loaded on the Organisational leadership for safety dimension but had low loadings; (3) the Supervisory leadership support for safety items loaded on two factors-one with the negatively phrased items and one with the positively phrased items; (4) five items had very low loadings or cross-loadings and were excluded from subsequent models. It is important to note that theoretical consideration was given to these five items and all other items removed at later stages of the factor analysis process. All removed items were either redundant, were further from the centre of the latent construct or had been flagged previously by Accreditation Canada as being inconsistently interpreted by survey respondents. Results are shown in online supplementary table S1, EFA column.

Based on the EFA results we tested a seven-factor model in CFA-1 that included 33 items. This model included the six dimensions from the EFA with the four items about managerial feedback and follow-up on errors as a separate (seventh) dimension. While there was some uncertainty about proposing and testing two factors of Supervisory leadership support for safety suggested by the EFA (one with negatively 
phrased items and one with positively phrased items), it was felt that both groups of items needed to be retained at this stage (implications of using negatively phrased items in surveys are included in the 'Discussion'). The CFA-1 model did not fit the data well (CFA- $1 \quad \chi^{2}=4095.45, \quad \mathrm{df}=474, \quad \mathrm{p}=0.000$, $\mathrm{CFI}=0.926$, RMSEA $=0.050$ ). Ten items that were not well accounted for by the model were excluded from CFA-2 and are shown with an asterisk in the CFA-2 column of online supplementary table S1.

The retrofitted seven-factor, 23 -item model produced good model fit in CFA- $2 \quad\left(\chi^{2}=1134.97\right.$, $\mathrm{df}=209, \quad \mathrm{p}=0.000, \quad \mathrm{CFI}=0.971, \quad \mathrm{RMSEA}=0.038$ ). However, CFA-3, which used multiple group CFA techniques, ${ }^{50}$ did not support invariance across the five care settings of interest in our sample (acute care medicine, long-term care, homecare, community care and ambulatory care) (baseline model $\mathrm{CFI}=0.944$, RMSEA $=0.021$ ).

After CFA-3 a decision was made to remove the negatively phrased supervisory leadership items-two of the items were not well accounted for by the CFA-3 model and the scale $\alpha$ for these three negatively phrased items was $<0.70$. The six-factor 19 -item model examined in CFA-4 produced good model fit $\left(\chi^{2}=641.63, \quad \mathrm{df}=137, \quad \mathrm{p}=0.000, \quad \mathrm{CFI}=0.981\right.$, RMSEA $=0.035$ ), and CFA-5 results largely support model invariance across these five settings $\left(\Delta \mathrm{CFI}=0.001, \Delta \chi^{2} \mathrm{p}=0.01\right)$.

Finally, results of CFA-6 support good model fit for the cross-validation sample $\left(\chi^{2}=906.07, \mathrm{df}=137\right.$, $\mathrm{p}=0.000, \quad \mathrm{CFI}=0.983$, RMSEA $=0.033$ ). Summary results of all six confirmatory models are provided in table 1 . The final path diagram is shown in figure 1. Item reductions that were made at each stage of the analyses described above are summarised in online supplementary table S1. The items shown in red text in online supplementary table S1 are the 19 items that were retained and are recommended for the final

Table 1 Confirmatory factor analysis summary results

\begin{tabular}{llll}
\hline CFA model & CFI & RMSEA & Fit assessment \\
\hline CFA-1 & 0.926 & 0.050 & Unacceptable \\
CFA-2 & 0.971 & 0.038 & Good \\
CFA-3 & 0.944 & 0.021 & Borderline \\
& $\Delta C F I=0.001^{*}$ & & \\
& $\Delta \chi^{2} p=0.000^{*}$ & & \\
CFA-4 & 0.981 & 0.035 & Good \\
CFA-5 & 0.960 & 0.028 & Good \\
& $\Delta C F l=0.001^{*}$ & & \\
CFA-6† & $\Delta \chi^{2} p=0.01^{*}$ & & \\
\hline
\end{tabular}

*Indices for measurement of invariance (the meaning of the six patient safety climate factors that is reflected in the number of factors and their items is equivalent across the groups).

tCross-validation sample.

CFA, confirmatory factor analysis; CFI, comparative fit index; RMSEA, root mean square error of approximation.
Can-PSCS measurement instrument. In addition, we recommend retaining two stand-alone items: "My organisation effectively balances the need for patient safety and the need for productivity' as it reflects the essence of PSC and, given the potential for welldesigned and easy to use reporting systems to foster safety culture, ${ }^{53}$ we also suggest retaining the item, 'Individuals involved in patient safety incidents have a quick and easy way to report what happened'. More detailed results of CFA- 1 through CFA- 6 are provided in the online supplementary appendix.

The internal consistency reliability of the Organisational leadership for safety, Supervisory leadership support for safety and Learning culture dimensions exceeded 0.80 for all care settings combined and approached or exceeded 0.80 for the five separate care settings individually (acute care medicine, longterm care, homecare, community care and ambulatory care). For the other three dimensions internal consistency reliability exceeded 0.70 for all care settings combined, and approached or exceeded that level for each of the five care settings individually.

\section{DISCUSSION}

The results of the validation work presented here support the six-factor, 19-item model tested in CFA-4, found invariant to care setting in CFA- 5 and crossvalidated in CFA- 6 . The results in online supplementary table S1 make clear that the 19 items in the final Can-PSCS tap six relatively distinct and theoretically important $^{5} 41 \quad 42$ dimensions of PSC: (1) Organisational (senior) leadership support for safety has four items and reflects perceptions of senior-level leadership commitment to patient safety; (2) Incident follow-up provides an expression of management commitment to safety and has three items about staff perceptions of whether there is feedback and change when incidents are reported; (3) Supervisory leadership for safety has two items and reflects perceptions of front-line-level leadership commitment to patient safety; (4) Unit learning culture has four items that reflect staff perceptions of learning from serious errors (ie, analysis of failures and plans to prevent reoccurrence). Dimensions (5) Enabling open communication I: judgment-free environment and (6) Enabling open communication II: job repercussions of error, each have three items and reflect perceived repercussions of error which can limit open communication. Our results make contributions to research and to practice. Each are described in turn.

\section{Contributions to research}

First, most CFA work on PSC instruments ${ }^{24} 25$ has yielded 'acceptable' model fit (eg, CFI exceeds 0.90) as defined by Bentler. ${ }^{54}$ While our CFA results are indicative of 'good' fit (CFI>0.95), ${ }^{36}$ less common indices of fit suggest our measurement model could be even more robust (see online supplementary 


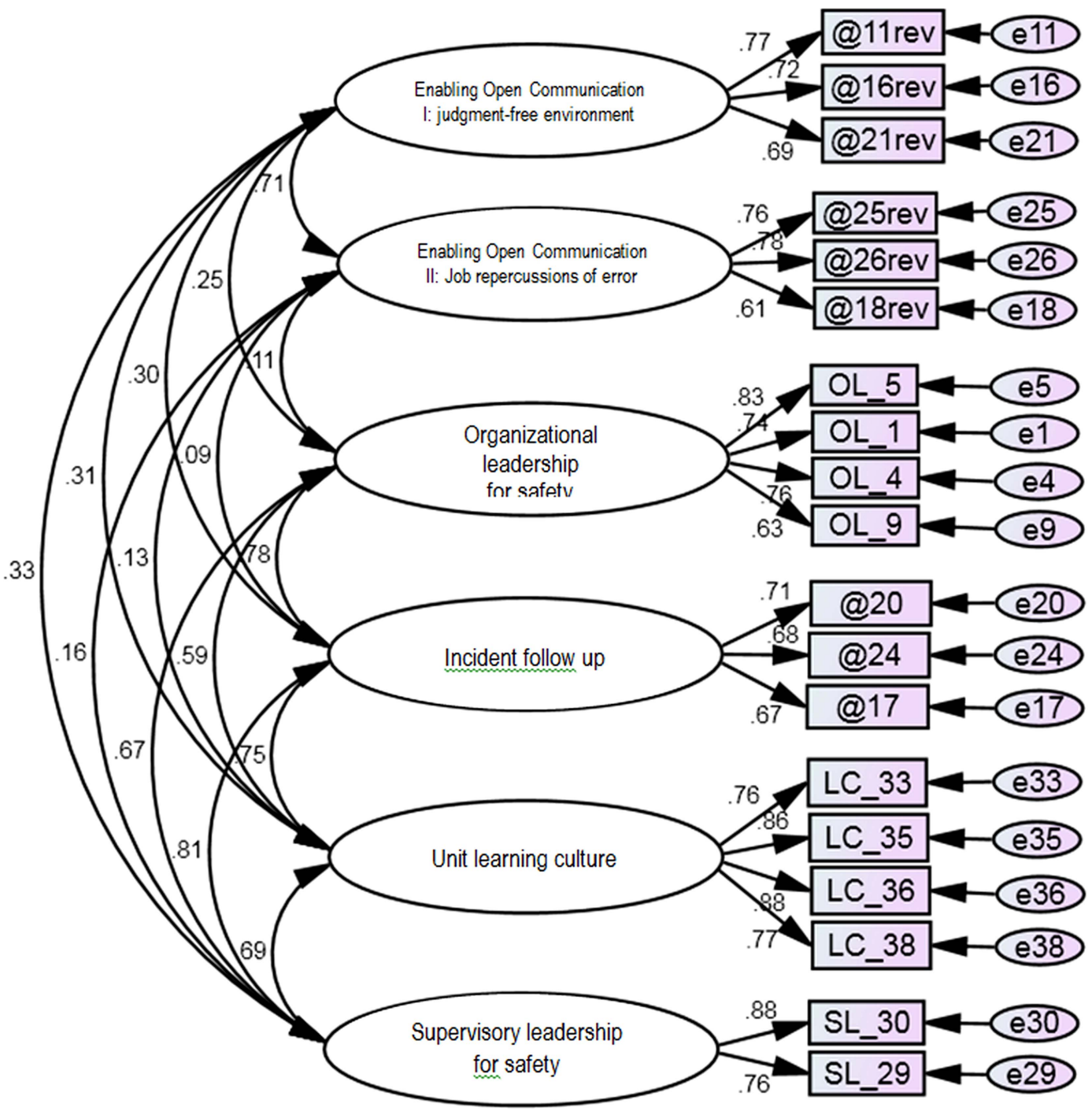

Figure 1 Final reduced six factor confirmatory factor analysis (CFA) model (outcome of CFA-6).

appendix CFA results). For instance, results of discriminant validity analysis (see online supplementary appendix) suggest the incident follow-up dimension shares a fair amount of variance with both the organisation-level and supervisory-level leadership dimensions, suggesting that these practices are perceived to be tied to leadership at both levels in an organisation. Our scale $\alpha$ values which are largely in the $0.70-0.80$ range are consistent with historical $\alpha$ values for perception scales, ${ }^{55}$ and meet recommendations for preliminary and basic research. ${ }^{55} 56$ However, values of $\alpha>0.90$ are recommended for applied research. So while the psychometrics we report are among the strongest for measures of PSC in healthcare, ongoing improvements to measurement of this construct continue to be required.

Second, by adhering to the PSC construct definition, we have endeavoured to contribute to much needed research on the dimensions or 'profile' of safety culture. ${ }^{26}$ In the past, definitions of the constructs of culture and climate, as well as more focused constructs of PSC, have been ambiguous ${ }^{21} 38$ and, perhaps as a result, a wide range of dimensions have been included in instruments that measure safety culture/climate. ${ }^{26}$ Data reported in this paper that have led to stronger psychometrics for the Can-PSCS than in previous versions of the instrument ${ }^{28}$ (as well as improvements others have made between early and more recent versions of the $\mathrm{PSCHO}^{22}$ ) are the result of removing survey items that reflect general perceptions of safety in favour of retaining items that, true to the concept of safety climate, ${ }^{21}$ reflect employee perceptions of safety behaviours that are valued and rewarded at multiple levels in an organisation.

Third, our results draw attention to potential methods effects in scaling when both positive and negatively phrased items are present. Negatively worded items are intended to act as 'cognitive speed bumps' that help people respond to questions carefully. ${ }^{57}$ However, sometimes constructs conceptualised as unidimensional may appear as multidimensional with positively and negatively worded items forming 
two separate factors. ${ }^{58}$ The initial bank of positive and negatively phrased items we used to measure supervisory leadership for patient safety seemed to show these kinds of systematic methods effects. Researchers who continue to work on the psychometrics of PSC measurement should be aware of these potential methods effects in scaling.

\section{Contributions to practice}

First, the Can-PSCS and the approach we used to evaluate its properties reflect progress on a number of broader patient safety fronts: (1a) the Can-PSCS can improve our ability to measure progress in safety improvement-an area where progress remains limited $^{16} ;(1 \mathrm{~b})$ it meets the need for greater use of theory to improve the science of patient safety ${ }^{59}$ and (1c) it makes progress on the relative inattention to safety in non-institutional settings. ${ }^{16} 2329$

Second, from a practice standpoint, additional contributions include the fact that the Can-PSCS: (2a) has been tested in a publicly funded universal health insurance system and so may be well suited to European and other international jurisdictions with similar healthcare systems; (2b) reflects a few actionable dimensions central to the construct of PSC, comprises only 19 items and can therefore be used quickly and frequently; and (2c) is designed and tested for use across a wide range of care settings and is therefore particularly well suited to regionalised healthcare delivery systems. Uniquely, the Can-PSCS is being used across settings by a national accreditation body and this presents opportunities to examine whether PSC is stronger in certain sectors or, as suggested by one reviewer, it may offer the potential for healthy competition or at least the setting of expectations about adequate levels of safety climate across settings.

Third, from an organisational standpoint, the Can-PSCS can be used: (3a) to assess the dimensions in which staff feel management commitment to patient safety is strong and weak; (3b) before patient safety improvement interventions in order to assess the context for change (eg, initiatives focusing on learning from errors can be more effectively designed when staff perceptions of 'enabling open communication' and 'unit learning' are understood); and (3c) during improvement initiatives to monitor intended as well as any unintended consequences. In each of these instances, achieving high response rates will greatly improve the value of the data collected. Other instruments that are designed to measure PSC, such as the Safety Attitudes Questionnaire and AHRQ tools, can also be used. In addition, these other tools can meet more specific needs-those who are seeking unit-focused measures of teamwork can use the Safety Attitudes Questionnaire ${ }^{25}$ and those seeking data on a broad range of safety and safety climate dimensions will find the AHRQ PSC survey ${ }^{24}$ very useful. Given stricter requirements for accountability, ${ }^{60}$ and the reality that public reporting can detract from improvement by shifting attention and resources elsewhere, ${ }^{61}$ we suggest that the Can-PSCS is more appropriately used for improvement and research than for public reporting.

\section{Limitations and future research}

This study has several limitations. First, the data were collected as part of the accreditation process and although this allowed for analysis of a large amount of data from direct care providers working across the continuum of care, detailed information on response rates and detailed respondent demographics were not captured during the data collection process. It is, however, unlikely that non-responders' conceptualisation of the dimensions of PSC would be structurally different. Second, there are questions about generalisability. It is possible that providers from other national cultures may find different meaning in the six PSC dimensions validated in this Canadian sample. Further research and cross-validation of the Can-PSCS will be required with international samples of direct care providers working in different care settings (one recent paper highlights the importance of international crossvalidation work $^{62}$ ). Relatedly, given that different groups of direct care providers such as physicians and nurses have differing perceptions of PSC, ${ }^{63}$ the field would benefit from additional research examining whether the Can-PSCS dimensions change with staff role. Third, Canadian healthcare settings are culturally diverse with a large proportion of providers with English as a second language. Additional validation work is required that explores validity in this context. Fourth, our study focuses on quantitative approaches to assessing patient safety culture. Organisations and work units wishing to understand their own patient safety culture are advised to use both quantitative and qualitative approaches to obtain the breadth and depth of understanding afforded by these two methods, respectively. Finally, our data came from a relatively small number of care providers dispersed across a large number of care units and organisations and therefore were not suitable for multilevel CFA.

Studies examining PSC at different levels (organisation, unit, profession) ${ }^{4064}$ continue to advance the field of PSC measurement; however, additional research is still needed. ${ }^{26}$ Such research would benefit from related debate in the organisational literature about the assessment of climate/culture strength. Culture strength involves both high levels of agreement among employees about what is valued and high levels of intensity about these values. ${ }^{65}$ In $2009^{28}$ we pointed out that consideration should be given to both the consensus approach (where consensus among individuals in their perceptions of climate is required before staff perceptions can be meaningfully aggregated to represent unit or organisational climate) and the dispersion approach (which suggests that lack of 
agreement among staff on a unit or in an organisation is important in and of itself as it is indicative of a weak climate) (see Schneider et $a l^{66}$ and Ostroff et $a l^{37}$ for further discussion).

Finally, given that organisations have several coexisting, domain-specific climates (eg, a safety climate, a justice climate and a work motivation climate), research that looks at multiple climates simultaneously is needed. ${ }^{21} 38$ This may be particularly useful for understanding the antecedents of a strong and positive $\mathrm{PSC}^{26}$ and the way in which different process climates interact and, in some cases, conflict (eg, suggestions to penalise staff for hand hygiene failures reflect the tension between 'no blame' and 'accountability' ${ }^{\text {'1 }}$ and may bolster the safety climate while damaging the organisational justice climate).

\section{CONCLUSIONS}

The Can-PSCS measures the perceptions of direct care providers about the kinds of behaviours that are rewarded and supported with regard to the specific strategic focus of patient safety. The survey has 19 items measuring six dimensions. Eight items are new and reflect different aspects of communication and talking about errors. Eleven items build on the work of others and measure organisational ${ }^{47}$ and supervisory $^{48}$ leadership for safety and unit learning culture. ${ }^{5}$ The Can-PSCS closely reflects the construct definition of PSC. The psychometric properties of the final item set are strong and promising for use with direct care providers in a wide range of care settings.

Acknowledgements We thank Michael Murray and Evan Castel for devising the communication/talking about error items. We also thank the thousands of staff in healthcare organisations who completed a patient safety culture survey. Finally, we are grateful to the reviewers and editors of the journal for the many valuable insights they provided during the revision, which were incorporated into the paper.

Contributors LRG designed data collection tools, methods and study design, analysed the data and drafted the paper. She is guarantor. DT and PGN contributed to overall study design and drafted and revised the paper. JIM and $\mathrm{HH}$ monitored data collection and revised the paper.

\section{Competing interests None.}

Ethics approval The study was exempt from review by the Human Participants Review Committee in the Office of Research Ethics at York University in Toronto as it exclusively used anonymised secondary data.

Provenance and peer review Not commissioned; externally peer reviewed.

Data sharing statement Study data may be available from the authors.

Open Access This is an Open Access article distributed in accordance with the Creative Commons Attribution Non Commercial (CC BY-NC 3.0) license, which permits others to distribute, remix, adapt, build upon this work noncommercially, and license their derivative works on different terms, provided the original work is properly cited and the use is non-commercial. See: http://creativecommons.org/licenses/by$\mathrm{nc} / 3.0 /$

\section{REFERENCES}

1 Kohn LT, Corrigan J, Donaldson MS. To err is human: building a safer health system. Washington, DC: National Academy Press, 1999.

2 Battles JB, Lilford RJ. Organizing patient safety research to identify risks and hazards. Qual Saf Health Care 2003;12 (Suppl 2):ii2-7.

3 Kagan I, Barnoy S. Organizational safety culture and medical error reporting by Israeli nurses. J Nurs Scholarsh 2013;45:273-80.

4 Snijders C, Kollen BJ, van Lingen RA, et al. Which aspects of safety culture predict incident reporting behavior in neonatal intensive care units? A multilevel analysis. Crit Care Med 2009;37:61-7.

5 Hofmann DA, Mark B. An investigation of the relationship between safety climate and medication errors as well as other nurse and patient outcomes. Pers Psychol 2006;59:847-69.

6 Mardon RE, Khanna K, Sorra J, et al. Exploring relationships between hospital patient safety culture and adverse events. J Patient Saf 2010;6:226-32.

7 Haynes AB, Weiser TG, Berry WR, et al. Changes in safety attitude and relationship to decreased postoperative morbidity and mortality following implementation of a checklist-based surgical safety intervention. BMJ Qual Saf 2011;20:102-7.

8 Singer S, Lin S, Falwell A, et al. Relationship of safety climate and safety performance in hospitals. Health Serv Res 2009;44 (2 Pt 1):399-421.

9 Neal A, Griffin MA, Hart PM. The impact of organizational climate on safety climate and individual behavior. Saf Sci 2000;34:99-109.

10 Clarke S. The relationship between safety climate and safety performance: a meta-analytic review. J Occup Health Psychol 2006;11:315-27.

11 Beus JM, Payne SC, Bergman ME, et al. Safety climate and injuries: an examination of theoretical and empirical relationships. J Appl Psychol 2010;95:713-27.

12 Dodek PM, Wong H, Heyland DK, et al. The relationship between organizational culture and family satisfaction in critical care. Crit Care Med 2012;40:1506-12.

13 Sorra J, Khanna K, Dyer N, et al. Exploring relationships between patient safety culture and patients' assessments of hospital care. J Patient Saf 2012;8:131-9.

14 Ginsburg LR, Tregunno D, Norton PG. Self-reported patient safety competence among new graduates in medicine, nursing and pharmacy. BMJ Qual Saf 2013;22:147-54.

15 Lempp HSC. The hidden curriculum in undergraduate medical education: qualitative study of medical students' perceptions of teaching. BMJ 2004;329:770-3.

16 Wachter RM. Patient safety at ten: unmistakable progress, troubling gaps. Health Aff (Millwood) 2010;29:165-73.

17 Bosk CL, Dixon-Woods M, Goeschel CA, et al. Reality check for checklists. Lancet 2009;374:444-5.

18 Gawande A. The checklist manifesto: how to get things right. New York: Metropolitan Books, 2009.

19 Pronovost P, Needham D, Berenholtz S, et al. An intervention to decrease catherer-related bloodstream infections in the ICU. N Engl J Med 2006;355:2725-32.

20 Haynes AB, Weiser TG, Berry WR, et al. A surgical safety checklist to reduce morbidity and mortality in a global population. N Engl J Med 2009;360:491-9.

21 Zohar D, Hofmann DA. Organizational culture and climate. In: Kozlowski S. ed. Oxford handbook of industrial and organizational psychology vol.1. New York: Oxford University Press, 2012:643-66. 
22 Singer SJ, Meterko M, Baker L, et al. Workforce perceptions of hospital safety culture: development and validation of the patient safety climate in healthcare organizations survey. Health Serv Res 2007;42:1999-2021.

23 Hartmann CW, Meterko M, Zhao S, et al. Validation of a novel safety climate instrument in VHA nursing homes. Med Care Res Rev 2013;70:400-17.

24 Sorra JS, Dyer N. Multilevel psychometric properties of the AHRQ hospital survey on patient safety culture. BMC Health Serv Res 2010;10:199, 6963-10-199.

25 Sexton JB, Helmreich RL, Neilands TB, et al. The Safety Attitudes Questionnaire: psychometric properties, benchmarking data and emerging research. BMC Health Serv Res 2006;6:44.

26 Singer SJ, Vogus TJ. Safety climate research: taking stock and looking forward. BMJ Qual Saf 2013;22:1-4.

27 Flin R, Burns C, Mearns K, et al. Measuring safety climate in health care. Qual Saf Health Care 2006;15:109-15.

28 Ginsburg L, Gilin D, Tregunno D, et al. Advancing measurement of patient safety culture. Health Serv Res 2009;44:205-24.

29 Castle NG, Wagner LM, Sonon K, et al. Measuring administrators' and direct care workers' perceptions of the safety culture in assisted living facilities. Jt Comm J Qual Patient Saf 2012;38:375-82.

30 Zwart DL, Langelaan M, van de Vooren RC, et al. Patient safety culture measurement in general practice. Clinimetric properties of 'SCOPE'. BMC Fam Pract 2011;12:117, 2296-12-117.

31 Waterson P, Griffiths P, Stride C, et al. Psychometric properties of the hospital survey on patient safety culture: findings from the UK. Qual Saf Health Care 2010;19:e2.

32 Pfeiffer Y, Manser T. Development of the German version of the hospital survey on patient safety culture: dimensionality and psychometric properties. Saf Sci 2010;48:1452-62.

33 Occelli P, Quenon JL, Kret M, et al. Validation of the French version of the hospital survey on patient safety culture questionnaire. Int J Qual Health Care 2013;25:459-68.

34 Sarac C, Flin R, Mearns K, et al. Hospital survey on patient safety culture: psychometric analysis on a Scottish sample. BMJ Qual Saf 2011;20:842-8.

35 Blegen MA, Gearhart S, O’Brien R, et al. AHRQ's hospital survey on patient safety culture: psychometric analyses. J Patient Saf 2009;5:139-44.

$36 \mathrm{Hu}$ L, Bentler PM. Cutoff criteria for fit indexes in covariance structure analysis: conventional criteria versus new alternatives. Struct Equ Model 1999;6:1-55.

37 Ostroff C, Kinicki AJ, Muhammad RS. Organizational culture and climate. In: Weiner I. ed. Handbook of psychology. 2nd edn. New York: John Wiley \& Sons, 2013:643-76.

38 Schneider B, Ehrhart MG, Macey WH. Organizational climate and culture. Annu Rev Psychol 2013;64:361-88.

39 Schein EH. Organizational culture and leadership, 4th edn. San Francisco: Jossey-Bass, 2010.

40 Zohar D, Luria G. A multilevel model of safety climate: cross-level relationships between organization and group-level climates. J Appl Psychol 2005;90:616-28.

41 Zohar D. Safety climate in industrial organizations: theoretical and applied implications. J Appl Psychol, 1980;65:96-102.

42 Zohar D. A group-level model of safety climate: testing the effect of group climate on microaccidents in manufacturing jobs. J Appl Psychol 2000;85:587-96.

43 Zohar D, Livne Y, Tenne-Gazit O, et al. Health care climate: a framework for measuring and improving patient safety. Crit Care Med 2007;35:1312.
44 Weaver SJ, Lubomksi LH, Wilson RF, et al. Promoting a culture of safety as a patient safety strategy: a systematic review. Ann Intern Med 2013;158(5 Pt 2):369-74.

45 Mitchell JI, Nicklin W, MacDonald B. The determinants of quality healthcare: implications for Canadian health leaders. Healthc Manage Forum 2012;25:138-41.

46 Ginsburg L, Norton PG, Casebeer A, et al. An educational intervention to enhance nurse leaders' perceptions of patient safety culture. Health Serv Res 2005;40:997-1020.

47 Singer SJ, Gaba DM, Geppert JJ, et al. The culture of safety: results of an organization-wide survey in 15 California hospitals. Qual Saf Health Care 2003;12:112-18.

48 Sorra J, Nieva VF. Psychometric analysis of the hospital survey on patient safety. Technical report delivered to the Agency for Healthcare Research o Quality (AHRQ). Rockville, MD: Agency for Healthcare Research and Quality; 2003, Report No.: 29-96-0004.

49 Reason J. Managing the risks of organizational accidents. Aldershot: Ashgate, 1997.

50 Byrne BM. Structural equation modeling with AMOS. 2nd edn. Routledge Academic, 2009.

51 Van Prooijen J, Van Der Kloot WA. Confirmatory analysis of exploratively obtained factor structures. Educ Psychol Meas 2001;61:777.

52 Schmidt K, Rees C, Greenfield S, et al. Multischool, international survey of medical students' attitudes toward "holism". Acad Med 2005;80:955-63.

53 Flemons WW, McRae G. Reporting, learning and the culture of safety. Healthc Q 2012;15:12-17.

54 Bentler PM. Comparative fit indexes in structural models. Psychol Bull 1990;107:238-46.

55 Peterson RA. A meta-analysis of Cronbach's coefficient alpha. J Consum Res 1994;21:381-91.

56 Nunnally JC. Psychometric theory. 2nd edn. New York: McGraw-Hill, 1978.

57 Podsakoff PM, MacKenzie SB, Lee JY, et al. Common method biases in behavioral research: a critical review of the literature and recommended remedies. J Appl Psychol 2003;88:879-903.

58 DiStefano C, Motl RW. Further investigating method effects associated with negatively worded items on self-report surveys. Struct Equ Model 2006;13:440-64.

59 Shekelle PG, Pronovost PJ, Wachter RM, et al. Advancing the science of patient safety. Ann Intern Med 2011;154:693-6.

60 Solberg LI, Mosser G, McDonald S. The three faces of performance measurement: improvement, accountability and research. Jt Comm J Qual Improv 1997;23:135-47.

61 Meyer GS, Nelson EC, Pryor DB, et al. More quality measures versus measuring what matters: a call for balance and parsimony. BMJ Qual Saf 2012;21:964-8.

62 Zúñiga F, Schwappach D, De Geest S, et al. Psychometric properties of the Swiss version of the nursing home survey on patient safety culture. Saf Sci 2013;55:88-118.

63 Huang DT, Clermont G, Sexton JB, et al. Perceptions of safety culture vary across the intensive care units of a single institution. Crit Care Med 2007;35:165-76.

64 Deilkas E, Hofoss D. Patient safety culture lives in departments and wards: multilevel partitioning of variance in patient safety culture. BMC Health Serv Res 2010;10:85, 6963-10-85.

65 Chatman JA, Cha S. Leading by leveraging culture. Calif Manag Rev 2003;45:20-34.

66 Schneider B, Salvaggio AN, Subirats M. Climate strength: a new direction for climate research. J Appl Psychol 2002;87: 220-9. 